\title{
Risks Associated with Next Generation Access Networks Investment Scenarios
}

\author{
Dimitris Katsianis, Theodoros Rokkas, loannis Neokosmidis, Markos Tselekounis, \\ and Dimitris Varoutas, University of Athens \\ loannis Zacharopoulos and Apostolia Bartzoudi, The Greek National Regulatory Authority
}

\begin{abstract}
The deployment of next generation access networks (NGAs) is investigated from technical, regulatory and investment perspectives. A brief review of the possible network architectures and deployment scenarios of NGAs is provided. Risk calculations of these NGA scenarios are performed based on a fully detailed techno-economic model. Furthermore, the effectiveness of the European Commission's Recommendation on regulated access to NGAs, aiming to tackle the regulatory trade-off between encouraging investments and promoting competition, is discussed.
\end{abstract}

$\mathrm{n}$ the last years, there has been an explosive growth of the Internet in terms of both the number of users and the transmitted volume of data. It is interesting to note that the aggregate volume of data circulated in the Internet is expected to increase with an annual growth of 30 percent for the next years [1] while the lowest demanded capacity by the end-users is doubled almost every two years [2]. Therefore, there is an increasing need for bandwidth resulting in new access methods.

In the case of access networks based on copper, there are several inherent technical and physical limitations setting barriers to performance such as maximum distance, bandwidth, and number of concurrent customers. On the other hand, access networks based on optical fibers are the only future-proof solution able to handle future demands [3], since the transmission capabilities of fiber are theoretically unlimited providing high data rates, low loss, and low distortion.

According to European Commission "Next generation access networks (NGAs) mean wired access networks which consist wholly or in part of optical elements and which are capable of delivering broadband access services with enhanced characteristics (such as higher throughput) as compared to those provided over already existing copper networks. In most cases NGAs are the result of an upgrade of an already existing copper or coaxial access network" [4]. Therefore, according to the EC two technologies are assumed as NGAs, fiber to the cabinet (FTTCab) and fiber to the home/building (FTTH/B).

There has been extensive discussion regarding NGA in recent years; however, the high cost of the development of NGA, in combination with the high uncertainties mainly on demand and revenues (which induce corresponding uncertainty on investment returns) and restrain service providers from

The positions illustrated in this article do reflect the personal opinions of the authors and not the official positions of the organizations that the authors are employed to. These official positions of the organizations are presented via their public announcements and official documents such as decisions, etc. investing in NGAs [5]. From this perspective, this article aims to identify, quantify, evaluate, and discuss the risk characteristics of the NGA.

The rest of the article is organized as follows. Initially the regulation framework regarding NGAs is presented. Technological options are illustrated. We report regulatory options related to NGAs and discuss the modeling assumptions. Results regarding the total risk are presented. Some concluding remarks are then given.

\section{NGA Regulation and Policy Framework}

Various policies are discussed and have been followed in order to overcome the uncertainty related to the deployment of NGA networks. The United States provided a regulatory holiday to two (geographically separated) operators in order to build their NGA networks, while other countries (mainly in Asia) have preferred the state-aid solution toward firms investing in NGAs.

The European Commission (EC) issued a Recommendation on regulated access to NGA [4] in order to provide National Regulatory Authorities (NRAs) with guidelines for tackling the trade-off between fostering competition and promoting investments with regard to NGAs.

In particular, the EC Recommendation is in accordance with Europe's overall regulation regime since it proposes that the access fees for any wholesale products should be based on a cost-based form.

This holds for any wholesale access product irrespective of whether it falls in the scope of the market for wholesale physical network infrastructure (usually named Market 4) or the wholesale broadband access (Market 5).

However, the EC Recommendation introduced the term of risk premium that should be included in the calculation of the costs of the wholesale access fees in order to compensate the investor ${ }^{1}$ for any additional and quantifiable risks incurred when investing in NGA networks. The principles of this premium calculation are described in detail in a special annex of the EC Recommendation. More specifically, this premium should reflect: 


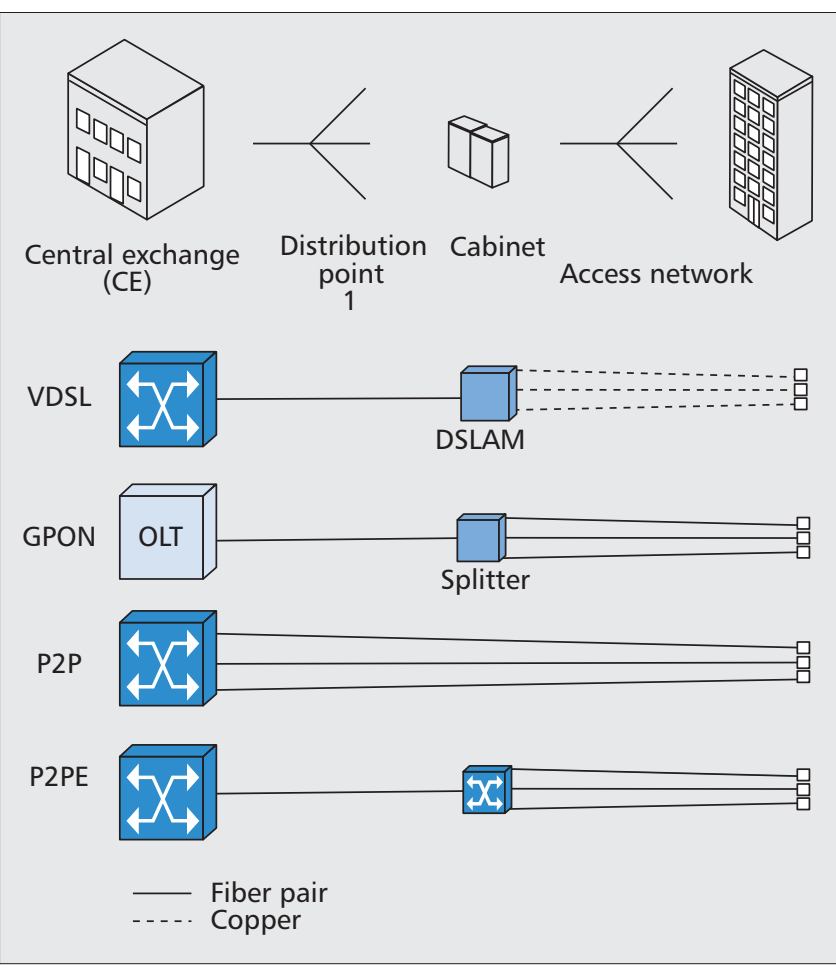

Figure 1. Examined architectures.

- Uncertainty relating to retail and wholesale demand

- Uncertainty relating to the costs of deployment, civil engineering works and managerial execution

- Uncertainty relating to technological progress

- Uncertainty relating to market dynamics and the evolving competitive situation, such as the degree of infrastructure-based and/or cable competition

- Macroeconomic uncertainty

It is worth mentioning that the incumbent operators usually claim that there is another risk factor called regulatory risk, which is related to the regulator's limited ability to make exante credible commitments.

\section{NGA Architectures Set by the EC Recommendation}

Although several architectures of access networks have already been proposed, including wireless ones, the EC proposed only fixed ones and always based on fiber [7]. In this article four alternative architectures are modeled and studied. One is fiber to the curb (FTTC) with very high rate digital subscriber line (VDSL), and the other three are FTTH.

\section{FTTC with VDSL}

Regarding the FTTC architecture, the path from the service provider's point of presence (POP) to the intermediate node (street cabinet) that serves an entire neighborhood exclusively consists of optical fiber (Fig. 1). A switch (digital subscriber line access multiplexer - DSLAM), placed on the street cabinet, is connected to the POP of the service provider via a fiber or a pair of optical fibers carrying the aggregated traffic from the neighborhood traffic usually through Gigabit Ether-

\footnotetext{
${ }^{1}$ It should be noted that the EC Recommendation tacitly implies that the incumbent will invest in NGAs, and the alternative operators will be the access seekers. OPTA [6] also argues that the prospective investors in $N G A$ networks are in large part former incumbent operators.
}

net. The access of each end user up to the switch of the street cabinet is realized using the standard copper cables used for the PSTN network and VDSL technology over copper cables. Depending on both the technology and the distance, end users experience symmetric or asymmetric data rates of up 100 $\mathrm{Mb} / \mathrm{s}$, depending on the copper length.

The FTTC architecture provides to the incumbent the advantage to connect its subscribers to existing copper cable infrastructure in the first mile. Additionally, it has lower capital requirements since the NGA investment is done only in part of the access network. However, it has limited time frame since there is a need for capacity doubling every two years.

\section{Fiber to the Home Scenarios}

According to the FTTH architecture, the path from the service provider's point of presence (POP) to the end user exclusively consists of optical fiber (Fig. 1). The fiber is terminated inside the home or workplace of the end user. Therefore, each device at the subscriber premises is connected through a dedicated optical fiber to a switch port located at POP or to the optical splitter which in turn connects to the POP via a single feeder fiber.

Three FTTH technologies are mature enough to use in an NGA investment. The choice of each technology depends on the type of the transmitted service, the infrastructure cost, the existing infrastructure and future plans towards new technologies.

Gigabit Passive Optical Network - In passive optical networks (PONs), each customer is connected to the optical network via a passive optical splitter. The advantages of an FTTH PON [8] are related to:

- The use of purely passive components between the central office and the end user

- Less requirements for fiber investment in the network segment LEX-outdoor cabinet

- Less space requirements inside the LEX since less fibers and thinner trenches are terminated at the LEX. The above issues lead to lower maintenance and operational costs. However, there are a number of disadvantages related to the GPON:

- Since a number of users (16-32 or a maximum of 64) share the capacity traveling over just one fiber, there are limitations on the maximum capacity per user.

- Due to the above, since there is congestion among the various users, it is mandatory to have resource protocols to run between LEX and users as well as to have more advanced customer premises equipment (CPE), such as burst receivers, compared to simpler CPE required for pure point-to-point (P2P) connections.

- The unbundling is limited by physical network resources.

The optical line termination (OLT) is the basic element of the network. It is usually placed at the central office $(\mathrm{CO})$ and is the driving force of FTTH systems. The optical network units (ONUs) are placed close to the end user. ONUs are connected to the OLT through optical fiber without using intermediate active components (Fig. 1).

Point-to-Point - Active Ethernet, also known as Ethernet switched optical (ESON) or P2P network, provides a dedicated optical fiber from the outdoor active equipment to each end user. In the case of $\mathrm{P} 2 \mathrm{P}$, operation, management, and maintenance as well as calculation of the power budget are greatly simplified due to the existence of this dedicated fiber. Core switch, aggregation, switch and the optical network terminal (ONT) are the main components of a P2P network (Fig. 1). Beyond the advantage of $\mathrm{P} 2 \mathrm{P}$ offering almost maxi- 
mum capacity $(100 \mathrm{Mb} / \mathrm{s}$ or $1 \mathrm{~Gb} / \mathrm{s}$ signal in a 100 BaseFX or 1000 BaseLX) to each end user, there is a main disadvantage: it requires the maximum invested capital since a fiber pair is dedicated to each user. Therefore, a large space for the ODFs inside the LEX should be available as in the case of copper networks, and the trenches (especially closer to the LEX) are expected to be wider (more complex and costly).

\begin{tabular}{lllll} 
Area & $\begin{array}{l}\text { Buildings } \\
\text { per cabinet }\end{array}$ & $\begin{array}{l}\text { Floors per } \\
\text { building }\end{array}$ & $\begin{array}{l}\text { Apartments } \\
\text { per building }\end{array}$ & $\begin{array}{l}\text { Density threshold } \\
\text { (customers/km }{ }^{2} \text { ) }\end{array}$ \\
\hline DU & 20 & 4 & 4 & 9000 \\
\hline U & 32 & 4 & 2 & 1000 \\
\hline S & 36 & 2 & 1 & 500 \\
\hline
\end{tabular}

Table 1. Area characteristics.

Point to Point Ethernet - In the P2P Ethernet (P2PE) scenario a first aggregation switch is located in the cabinet between the central office and the user premises. The architecture is similar to the one of GPON with the difference that there is active equipment in the cabinet (Fig. 1). This technology seems to accommodate the pros and cons of all other technologies:

- Requires power in the field

- Might offer higher capacity per user that FTTC/VDSL and GPON but in any case lower than the maximum provided by the pure $\mathrm{P} 2 \mathrm{P}$ technology

The specific technology could be the migration of a FTTC/VDSL network since the power could be already available or of a GPON network since fiber is available and only changes to outdoor cabinet should be performed.

\section{NGA Regulatory Options}

\section{The Main NGA Risk Factor: The Risk of Future Demand for New Fiber-Based Services}

Demand and penetration are the main factors which cause risks related to NGA investments [9]. The higher the penetration of the potential customer base is, the higher the profitability of the investment becomes. Moreover, if the penetration does not reach the critical mass that is required for the creation of the new fiber-based services market, the NGA investment may not even be profitable at all.

There are three factors that influence the penetration of the new fiber-based services. First, the existence of competing NGA fiber network platforms, such as cable networks, increases the risk of both penetration and investor's market share. In particular, the higher the degree of facilities-based competition is, the higher the risk of both penetration and investor's market share becomes. Secondly, the co-existence of a remaining copper network DSL platform and a new fiber NGA platform increases the risk of the future demand for the new fiber-based services. In particular, the higher the migration period from copper-based services towards NGA-based services, the higher the risk of the penetration of the new NGAbased services. Last, but not least, the risk of sufficient willingness to pay (WTP) increases the risk of future demand for new fiber-based services.

Although, it is expected that the WTP for the new services will be higher than the WTP for the existing services since the former offer improved characteristics, such as better quality and higher data rate, it is doubtful that this increase in consumers' WTP will be sufficient for recovering the high investment cost.

\section{Regulatory Policy}

A regulator's goal is twofold. First, it aims to encourage investments in order to promote innovation and market growth; second, to foster competition in the retail market in order to ensure lower prices, better quality, and higher social welfare. Taking into account that the EC recommendation sets a predetermined framework to follow, and that in any case a regulatory holiday is not a desirable option, a European regulator has many different means in order to affect both investments and competition. Initially, the regulator should decide about the regulatory regime (e.g. access levels and corresponding wholesale access products, etc). According to the above decision, the regulator should then decide about specific parameters of the regulatory policy, such as the regulatory period (i.e., the interval between two reviews of the regulatory policy), the risk premium and other complementary regulatory options (e.g. adoption of risk sharing schemes, adoption of a transparent framework for the migration path from copper to fiber-based networks, etc).

The impact of each decision on investment and competition varies significantly. Some regulators are in favor of encouraging investments more than fostering competition. Therefore, there is a trade-off between promoting investments and fostering competition. In any case, regulatory certainty is expected to promote investment in NGA. This requires the regulator's ex ante commitment to its decisions for a long period, the economic lifetime of an NGA investment, but especially in the first and most crucial time period.

In the following analysis, it has been assumed that NRAs adopt and implement the EC Recommendation on regulated access to NGA. Therefore, the access to wholesale physical network infrastructure (Market 4) as well as, the wholesale broadband access (Market 5 ) should be mandated and costoriented. In addition, NRAs should be able to calculate and include a higher risk premium to reflect any additional and quantifiable investment risk incurred by the investor. This risk premium should be incorporated into the weighted average cost of capital (WACC) calculation for setting the price of access to the unbundled copper loop.

\section{Techno-Economic Model \\ Risk Calculation}

The tool used in this study is the ECOSYS techno-economic tool, which has been used in the evaluations of various wireless and wireline access technologies. The application of the model relies on its database, where the cost figures of the various network components are kept and constantly updated from data gathered from the biggest European telecommunication companies. Further information can be found in [5]. The outputs of this model are:

- The investments undertaken by the incumbent

- The unit costs of the various retail and wholesale products

- The risk premium associated with the specific investment

In order to make the above calculations, the tool creates a modeled NGA network in a bottom-up (BU) long run incremental cost (LRIC) approach. BU stands for the approach of creating the appropriate scale/footprint of the network that the foreseen demand requires. Therefore, proper dimensioning rules are followed to tailor the necessary type and volume of components to the expected services' demand. The LRIC approach mainly means that the only the NGA increment is modeled, and no other network that might be complementary to NGA (e.g., a leased line core network). For the first two of 
the above outputs, the volumes of the necessary components are calculated based on the demand, and the unit costs of the various necessary components are used. For the last calculation which is the risk premium, it is necessary to account future cash flows according to the recommendation. Therefore, assumptions for the revenues and their evolution over time should be made.

By combining the revenues and expenditures sides, namely service revenues, investments, operating costs and general economic inputs (e.g., discount rate, tax rate), the tool calculates the results necessary for discounted cash flow (DCF) analysis such as cash flows, net present values (NPVs), internal rate of return (IRR), payback period and other economic figure of merits for the NGA investor. The risk factor, which is the main output parameter that will be presented in the following sections, is defined as the difference the standard (traditional) WACC minus the IRR of the NGA project following discussion in [9].

Total NGA risk factor $=$ Traditionally defined operator $W A C C$ - the IRR of the NGA project

This is called total risk, and it should not be misinterpreted as the risk premium reported in the recommendation. The total risk refers to how much higher should the IRR of an NGA project be than the traditional WACC of an operator (which is based on all other operator's activities, mainly traditional ones: voice, access, leased lines, etc.). In the following paragraphs, the total risk to which the operator will be exposed if making the decision to implement an NGA is calculated and discussed for the four scenarios studied.

\section{Modeling Assumptions}

The model calculates all the necessary costs and revenues the incumbent will face if it makes the decision to implement an NGA in an area that is served from one central office. Each area according to its density (customers/square $\mathrm{km}$ ) is characterized as dense urban (DU), urban (U), or suburban (S), and for each area there are different assumptions concerning the number of buildings and other geographical parameters presented in Table 1.

The incumbent offers services to both retail and wholesale broadband markets. The project's study period is set to 20 years, beginning in 2011. For the first 10 years of the analysis full dimensioning of costs and revenues is performed. However, for the next 10 years the following assumptions have been used, since it is very difficult to make long-term estimations and prognoses. The cost of investments was assumed to remain at the same levels as in the last three years ( 7 th-10th year) of the analysis. For both revenues and running costs a linear estimation was performed, taking into account again the last three years.

The WACC pre-tax has been assumed as 10.5 percent (defined as a mean value among European incumbent operators), and it has also been used as the discount factor in the DCF analysis.

As far as the broadband products offered and the forecasted revenues, the following assumptions have been used. Two retail products (lower and higher) offered by the NGA investor were modeled $(30 \mathrm{Mb} / \mathrm{s}$ and $50 \mathrm{Mb} / \mathrm{s}$ for FTTC, and $75 \mathrm{Mb} / \mathrm{s}$ and $100 \mathrm{Mb} / \mathrm{s}$ for FTTH scenarios). Two corresponding wholesale broadband products (wholesale broadband access [WBA] or bitstream) were assumed to offer to the access seekers. For simplicity reasons their price was set at retail - 20 percent, but it is possible to set them at a cost-oriented level (with or without risk premium). Moreover, wholesale physical access products were assumed to be priced at

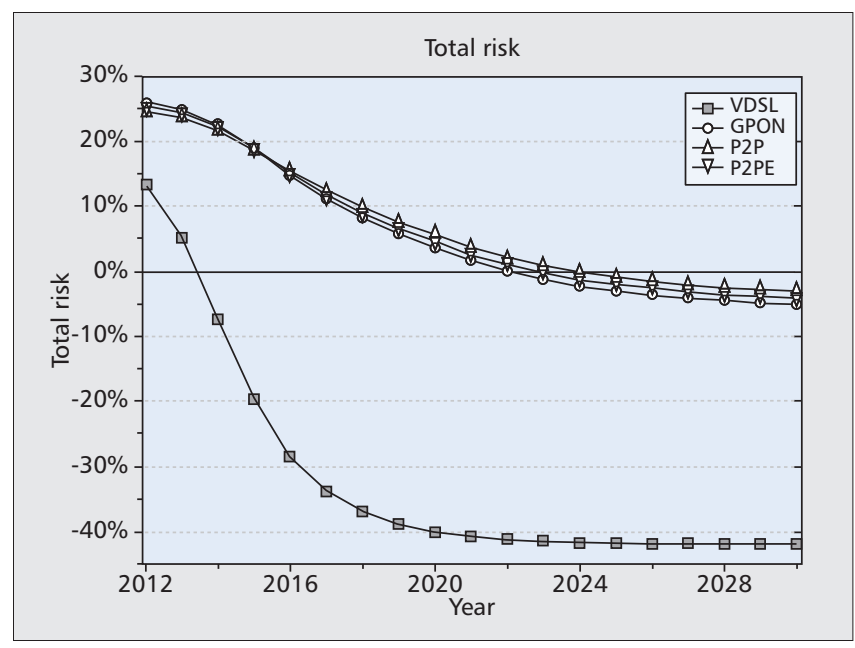

Figure 2. Total risk for all architectures.

cost-oriented level without premium. ${ }^{2}$ The mix of WBA and physical access products is $50-50$ percent. It is assumed that the NGA investor has an initial NGA retail market share of 90 percent, which in the 10 th year has been reduced to 70 percent due to competitive pressure by access seekers. The revenue has been assumed almost constant during the time period examined. This is consistent with the approach followed by almost all operators and in almost all countries to keep the same revenue and offer higher speed to consumers or make some offers over time. A 2 percent tariff yearly reduction has been assumed due to these offers.

\section{Results}

As a first step in the analysis, a total number of ten geographic areas have been selected with 320.000 potential subscribers in total. Three of them were characterized as DU, five as U and the rest three as S. The model calculated the total risk for the case that the incumbent operator decides to deploy the same architecture solution to all the areas for all 4 architectures.

Negative total risk means that the IRR of the NGA project itself is higher than the traditionally calculated WACC of the operator-investor, thus the NGA project can be considered as profitable as the current (traditional) investment. In other words negative or even small positive but close to zero values indicate that the risk of the specific scenario is rather minimal. Obviously, for the 3 FTTH scenarios this profitability can be observed only after many years of operation, verifying all worldwide discussion about the risks entailed to the FTTH/NGA investment. The launching period of FTTH/NGA operation is the most crucial since it is characterized by high risks, due to all parameters already discussed, and mainly to low penetration, adoption, or demand. Therefore, it is verified how strategic the role of the regulator is during this first NGA operation interval. The regulatory decisions taken ex ante (i.e., during this first NGA operation interval) should be the optimum in order to avoid altering this risk profile and perhaps worsening it.

As can be seen in Fig. 2, the three FTTH architectures have more or less the same risk, and the FTTC scenario is significantly better. It is worth mentioning that FTTC/VDSL2 has much less risk than the others due to the lower capital required to invest (mainly less trenching). Therefore, the fre-

\footnotetext{
${ }^{2}$ Different pricing schemes can be evaluated, but such an analysis is beyond this article's scope.
} 


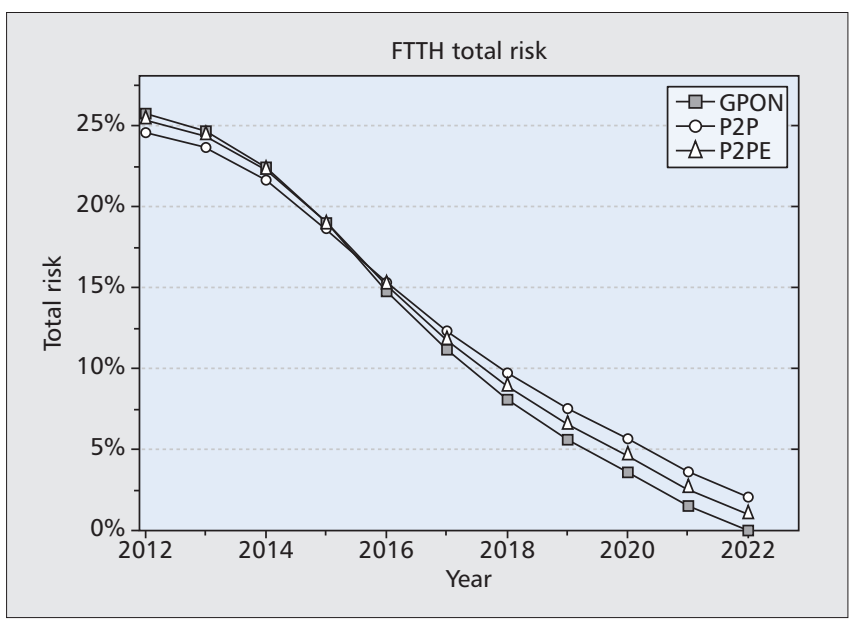

Figure 3. Total risk for FTTH architectures.

quent comment of incumbent operators that FTTC/VDSL2 entails significant risks loses its validity especially when compared to the other technologies. It is worth mentioning that profitability of this FTTC/VDSL scenario is achieved in less than five years. This is attributed mainly to the highly urban nature of the selected mix of areas modeled. Risks of FTTC/VDSL2 investment are considerably reduced in dense urban and urban areas.

Figure 3 focuses on FTTH architectures only, while the study period is limited to only the first 10 years. It is worth mentioning that the risk levels of the three FTTH technologies are more or less the same, although their pros/cons profiles are different. This indicates that a more detailed analysis should be followed, and special attention should be paid regarding the cost assumptions for each of GPON, $\mathrm{P} 2 \mathrm{P}$, and P2PE technologies. Beyond FTTCab/VDSL2, which has in general less risk, there should be careful calculation for risk associated with FTTH technologies. In case of any FTTH technology for a time interval of the investment at 10 years, a minor but positive value less than 3 percent is occurring (Fig. 3 ). This can be interpreted as profitable within a 10 -year period, even for those risky investments and despite the usual utility-like investments that are profitable beyond the time period of 20 years. However, this medium-term profitability can be secured when a number of contributing factors hold cumulatively:

- A relative revenue (i.e., average revenue per user [ARPU]) stability over time during this time interval; that is, no price war situations among access providers and access seekers

- Rollout cost reduction by strategies like co-investment among access providers, access seekers, and possibly other parties, state/municipality facilitation, and so on

- Regulatory stability and close monitoring relaxing in case of the pertinent risk profile

- Demand aggregation by state aid or even facilitation In particular, the regulators face a big dilemma for the FTTH cases. If they follow the recommendation they have to calculate a risk factor that probably will be high. This factor must be used to reward the NGA investor; as a result, this risk premium would raise the unit cost (i.e., the tariffs of both retail and wholesale services). If these tariffs are set initially at high prices, the demand for these prices should face even more risk and might lead the NGA investment to a total sunk cost with fewer possibilities of profitability. If they do not follow the recommendation regarding the cost orientation basis (which is not easy to prove to the EC), alternative schemes should be invented. For example:

- The retail tariffs can be set by the operators according to their own commercial policies, which might accept short-

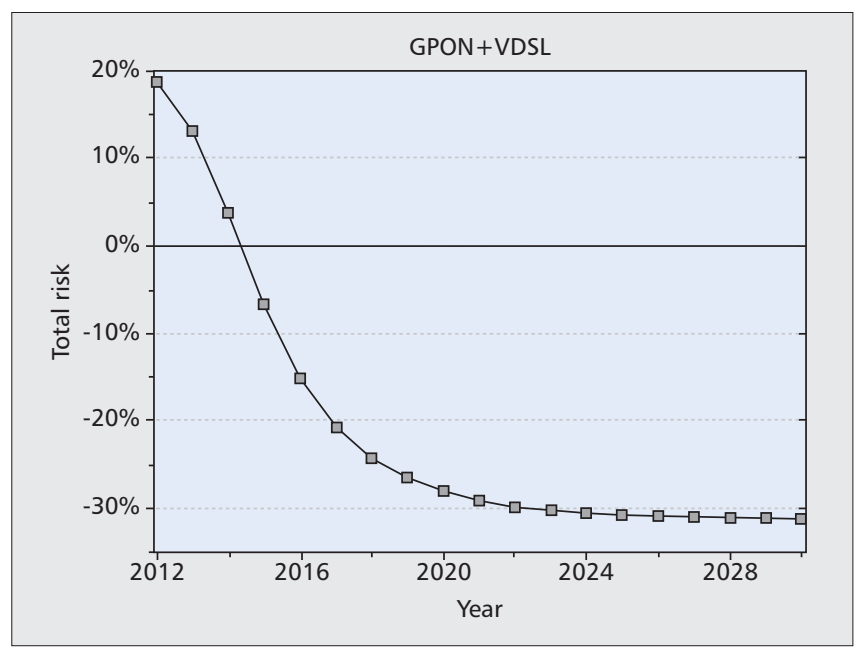

Figure 4. Total risk for GPON+VDSL scenario.

term losses in order to gain a wider customer base or in an anchor pricing form [10].

- Wholesale prices can be set on a retail-minus basis or other alternatives indicated by the European Regulatory Framework and common practices.

However, these strategies can easily lead to price wars, which at the end of the day might push all operators to limited profitability (or even into the negative).

At the next step, a new scenario was created in which the incumbent implements a mixed roll-out scenario deploying FTTH/GPON in the three DU areas and FTTC/VDSL in the rest seven areas. With this solution the incumbent avoids using the costly FTTH technology in areas with low customer density and reuses part of the already installed copper network. The total risk for the incumbent-investor was calculated and the results are presented at Fig. 4.

As expected, the risk calculated falls between the cases of pure FTTH-GPON and VDSL scenarios. The risk of this investment scheme is significantly lower than the GPON one. The total risk seems to be close to zero in about four years time, indicating higher possibility to project profitability. This indicates that the optimum strategy by the investing operator shouldn't follow just one technology. On contrary, and as expected, in areas with low expected demand and/or customer purchasing power risky investments should avoided. Regulators' challenges in these cases are related towards ensuring access of all consumers and access seekers to all technologies/areas perhaps by geographical remedies.

Finally, in order to further clarify the parameters that affect the total risk a sensitivity analysis was made in the risk value of the above modeled scenario at the 10th year. The impact of some critical parameters (such as the revenues, the penetration and the cost for digging and constructing the network, not the equipment cost) was examined. In sensitivity analysis each parameter is changed in order to study the impact that the changes in each parameter have to the output variable (while the others remain constant). The results are presented at Fig. 5. Each parameter was changed within an interval of \pm 20 percent of their initially assumed values. The most important impact is that of the revenue followed by the penetration and, finally, the digging cost. It should be denoted that if the case was purely FTTH the impact of the digging cost would be significantly higher. This result regarding the impact of revenue on risk confirms our previous discussion in Fig. 3 about the important role of ARPU stability over time in an NGA environment. Anything that could contribute to avoidance of a price war in NGA environment would be welcome (regulatory or not, e.g., state aid ). Price wars have been a 


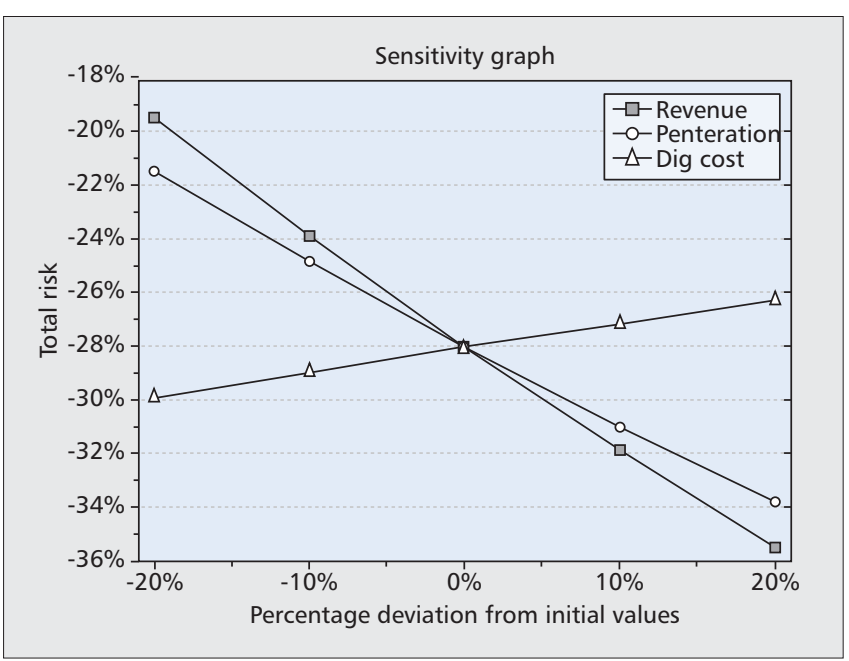

Figure 5. Sensitivity graph for GPON+VDSL scenario.

common practice in many sectors including traditional telecoms; however, price wars in the NGA era would likely push/force every involved actor to exit the market.

\section{Conclusions}

The risk profile of NGA investments has been quantified, analyzed, and discussed under different scenarios for the first time according to our knowledge. It seems that FTTC/VDSL2 does not have a significant risk profile due to its high reuse of a significant portion of the existing copper public switched telephone network (PSTN). This investment is expected to be profitable in less than five years, although some incumbent operators claim high risk for this technology as well.

All FTTH technologies have more or less the same risk profile, but further examination is required. The risk profile of all is very high during the launching period but reduces to almost zero after about a decade. This means that the NGA investment has lower duration than utility-like investments, but its risk is high, especially in the first years of operation.

Taking into account the above, it is crucial for all involved parties (operators, regulators, EC, states, etc.) to understand all these risk factors of the NGA investment itself. The NGA risk forces all to cooperate in order to minimize it; otherwise, there will be no NGA at all. The access seekers should not based only on regulator's remedies to keep their operations in an NGA environment. Even in the worst case for NGA investor regime (cost-orientation with premium) the accessseekers have to pay high access price. Therefore, they should not follow a price war policy in the retail market.

The NGA investor should benefit from a risk premium but this premium should not be too high otherwise it will kill its retail price too. In a NGA environment the operators cannot continue their policy that they have used to in the current business environment. On contrary they should share their risk. The EC recommendation offers a number of tools but unfortunately some of these (like cost-orientation combined to risk-premium) possibly does not lead to risk relax, while some others do facilitate the risk sharing.

Credibly, the regulators should be in a position to accept a long-term NGA policy with close monitoring and perhaps other policies/tools beyond standard cost-orientation approach (at least for a temporal/transition period).

The EC, which issued the NGA recommendation, must understand there are many practical details resulting from what is described in this recommendation. The cost orientation combined with premium is leading to high wholesale access prices. If retail prices are kept below these whole- sale access prices in order to attract a customer base, the EC should accept that at least in the short term, predatory pricing is a temporal sacrifice due to the well understood NGA risk. Unfortunately, this NGA recommendation does not consider the details in such cases, and perhaps could deserve further review. But fortunately, the EC NGA recommendation depicts that risk sharing is accepted. The risk sharing via co-investment or other schemes should be the basis for the NGA operators (investors and access seekers)

The Member States may play the most important role since they can make higher- or lower-grade interventions for facilitation of NGA deployment. For example, these interventions could include proposals for state-aid measures regarding NGA deployment, facilitation measures such as demand stimulation/subsidization, network facilitation such as relaxation on the rights of way, and so on. Some of the above NGA risks could be waived (at least partially) after a successfully designed measure initiated by a State or an arm of it.

\section{Acknowledgment}

The authors acknowledge their colleagues in the Greek NRA and the University of Athens for their useful support and discussion.

Tselekounis Markos acknowledges financial support from the European Union (European Social Fund - ESF) and Greek national funds through the Operational Program "Education and Lifelong Learning" of the National Strategic Reference Framework (NSRF) - Research Funding Program: HeracleitusII, investing in knowledge society through the ESF.

\section{References}

[1] Cisco Visual Networking Index: Forecast and Methodology, 2010-2015 http://www.cisco.com/en/US/solutions/collateral/ns341/ns525/ns537 /ns705/ns827/white_paper_c1 1-481360.pdf

[2] J. Nielsen, "Nielsen's Law of Internet Bandwidth," 05-1998, retrieved from http://www.useit.com/alertbox/980405.html.

[3] P. W. Shumate, "Fiber-to-the-Home: 1977-2007," J Lightwave Tech., vol. 26, no. 9-12, May-June 2008, pp. 1093-103.

[4] EC, 2010, Commission Recommendation on regulated access to Next Generation Access Networks (NGA), retrieved from: http://eurlex.europa.eu/LexUriServ/LexUriServ.do?uri=OJ:L:2010:251: 0035:0048:EN:PDF

[5] T. Rokkas, D. Katsianis, and D. Varoutas, "Techno-Economic Evaluation of FTTC/VDSL and FTTH Roll-Out Scenarios: Discounted Cash Flows and Real Option Valuation," J. Opt. Commun. Net., vol. 2, issue 9, Sept. 2010, pp. 760-72.

[6] Onafhankeliike Post en Telecommunicatie Autoriteit (OPTA), May 2010. Regulation, risk and investment incentives, Regulatory policy note 06 , retrieved from: http://www.opta.nl/en/news/all-publications/publication/ id $=3201$.

[7] C. Lin, Broadband Optical Access Networks and Fiber-to-the-Home: Systems Technologies and Deployment Strategies, 1 st ed., Wiley, 2006.

[8] C. F. Lam, Passive Optical Networks: Principles and Practice, 1st Edition, Academic Press, 2007.

[9] OPTA, 2008, "Policy Rules Tariff Regulation for Unbundled Fiber Access," retrieved from http://www.opta.nl/en/news/allpublications/publication/? id=2832.

[10] H. Ergas et al., "Price Squeezes and Vertical Discrimination on Next Generation Access Networks," retrieved from http://ssrn.com/abstract $=1433170$.

\section{Biographies}

DIMITRIS KATSIANIS (dkats@di.voa.gr) received his Informatics degree, M.Sc. in signal processing and computational systems, and Ph.D. in network design with technoeconomics aspects from the University of Athens Department of Informatics and Telecommunications. He is a senior research fellow with the Optical Communications Group, participating in several European and national R\&D projects. He has worked as an expert scientific advisor with several firms in the field of technoeconomic and network design including national activities for technoeconomic evaluation of telecommunication strategies and regulation policies. He has more than 60 
publications in journals and conferences in the field of technoeconomics and telecommunication network design.

THEODOROS ROKKAS (trokkas@di.uoa.gr) received his B.Sc. degree in physics, M.Sc. degree in electronics and radio communications, and Ph.D. degree on Techno-Economic Evaluation of Next Generation Networks from the University of Athens, Greece. He has actively participated in several techno-economic activities for telecommunications, networks, and services, and in several European and national R\&D projects. His research interests include techno-economic evaluation of network architectures and services, mobile communication systems, broadband and wireless systems and networks, and methodologies for network design.

IOANNIS NEOKOSMIDIS (i.neokosmidis@di.uoa.gr) holds a physics degree, an M.Sc. in radioelectrology and electronics, and a Ph.D. in optical nonlinear networks from the University of Athens. He is currently a research associate at the University of Athens and an adjunct lecturer at Harokopion University. He has participated in European and National projects. He has 31 publications, 91 citations, and two best paper awards. His research interests include system of systems, deep uncertainties, optical communications, and technoeconomics.

MARKOS TSELEKOUNIS (markos@di.uoa.gr) received an economics degree from the University of Piraeus and an M.Sc. degree in telecommunications economics from the University of Athens. He is currently a Ph.D. candidate and research associate at the University of Athens. His research interests include regulatory economics, network economics, and industrial organization. He has several publications in refereed international journals and con- ferences. He has been participating in numerous European and national projects as an economic analyst.

IOANNIS ZACHAROPOULOS is now with the Hellenic Telecommunications \& Post Commission, which is the Greek national regulatory and competition authority responsible for the telecom market (www.eett.gr). His work is mainly focused on next generation access (NGA), cost control andcost accounting in telecom networks, market analyses, competition issues (price squeeze, etc.), and techno-economic modeling of telecom networks. In the past he worked for the main telecom companies in Greece, including operators and vendors. He received a B.Sc. (1994) in physics, and an M.Sc. (1996) and a Ph.D. (2000) in telecom engineering

APOSTOLIA BARTZOUDI is currently working at the Hellenic Telecommunications \& Post Commission. Her main areas of expertise involve cost control, and regulatory and competition economics with focus on wholesale access markets and NGA. In the past, she worked for a large Greek telecom operator and international consulting companies. She received a B.Sc. (1996) in international and European economics and an M.Sc. (1998) in finance and investment.

DIMITRIS VAROUTAS [SM] (D.Varoutas@di.uoa.gr) holds a physics degree, and M.Sc. and Ph.D. diplomas in communications and technoeconomics from the University of Athens. He serves as an assistant professor in the Department of Informatics and Telecommunications at the University of Athens. He has published more than 90 publications in refereed journals and conferences in the area of telecommunications, optoelectronics, and technoeconomics. 